\title{
SUSCETIBILIDADE DE Ipomoea quamoclit, I. triloba e Merremia cissoides aOS HeRbicidas SUlfentrazone E AMICARBazone ${ }^{1}$
}

\author{
Susceptibility of Ipomoea quamoclit, I. triloba and Merremia cissoides to the Herbicides \\ Sulfentrazone and Amicarbazone
}

\author{
CAMPOS, L.H.F. ${ }^{2}$, FRANCISCO, M.O. ${ }^{3}$, CARVALHO, S.J.P. ${ }^{4}$, NICOLAI, M. ${ }^{4}$ e \\ CHRISTOFFOLETI, P.J. ${ }^{5}$
}

\begin{abstract}
RESUMO - A suscetibilidade diferencial de espécies de plantas daninhas a herbicidas é uma importante variável que deve ser considerada na escolha do herbicida e dose a serem aplicados. Assim, dois experimentos foram desenvolvidos com o objetivo de avaliar a suscetibilidade de três espécies de plantas daninhas da família Convolvulaceae (Ipomoea quamoclit, I. triloba e Merremia cissoides) aos herbicidas sulfentrazone e amicarbazone, por meio de curvas de dose-resposta. Os experimentos foram instalados em área com solo argiloso, onde foram aplicadas oito doses de cada herbicida, em pré-emergência. As doses utilizadas foram 8D, 4D, 2D, D, 1/2D, 1/4D, 1/8D e testemunha sem aplicação, sendo D a dose recomendada de sulfentrazone $\left(600 \mathrm{~g} \mathrm{ha}^{-1}\right)$ ou de amicarbazone (980 $\left.\mathrm{g} \mathrm{ha}^{-1}\right)$. As doses recomendadas de ambos os herbicidas foram eficazes para controlar as três plantas daninhas nas avaliações realizadas até os 60 dias após aplicação. Observou-se suscetibilidade diferencial entre as espécies estudadas, em que I. quamoclit foi a mais sensivel. As ordens de suscetibilidade das espécies aos herbicidas foram: I. quamoclit $\geq M$. cissoides $\geq I$. triloba para o sulfentrazone; e I. quamoclit $\geq$ I. triloba $\geq M$. cissoides para o amicarbazone. Os niveis de controle indicam a viabilidade de aplicação de sulfentrazone e amicarbazone em préemergência para controle dessas espécies de plantas daninhas da família Convolvulaceae.
\end{abstract}

Palavras-chave: Convolvulaceae, corda-de-viola, pré-emergência, dose-resposta, manejo.

\begin{abstract}
Differential susceptibility of weed species to herbicides is an important variable that must be considered when choosing the herbicide and rate to be applied. Thus, two experiments were carried out with the objective of evaluating the susceptibility of three weed species of the Convolvulaceae family (Ipomoea quamoclit, I. triloba and Merremia cissoides) to the herbicides sulfentrazone and amicarbazone, using dose-response curves. Trials were installed in an area with clay soil, where eight rates of each herbicide were applied, in pre-emergence. The herbicide rates were: $8 D, 4 D, 2 D, D, 1 / 2 D, 1 / 4 D, 1 / 8 D$ and check without application, considering $D$ as the recommended rate for sulfentrazone $\left(600 \mathrm{~g} \mathrm{ha}^{-1}\right)$ or amicarbazone $\left(980 \mathrm{~g} \mathrm{ha}^{-1}\right)$. Recommended rates of both herbicides were effective to control the three weed species, in the evaluations performed up to 60 days after application. Differential susceptibility of weed species to herbicides was observed, characterizing I. quamoclit as the most sensitive species. The susceptibility scales were: $\boldsymbol{I}$. quamoclit $\geq \boldsymbol{M}$. cissoides $\geq \boldsymbol{I}$. triloba for sulfentrazone; and $\boldsymbol{I}$. quamoclit $\geq \boldsymbol{I}$. triloba $\geq \boldsymbol{M}$. cissoides for amicarbazone. Control levels indicate that application of sulfentrazone and amicarbazone in pre-emergence is viable to control these weed species of Convolvulaceae.
\end{abstract}

Keywords: Convolvulaceae, morningglory, pre-emergence, dose-response, management.

1 Recebido para publicação em 13.8.2008 e na forma revisada em 13.11.2009.

2 Biólogo, Grupo São Martinho S.A., Iracemápolis-SP; Mestrando em Fitotecnia, Escola Superior de Agricultura "Luiz de Queiroz" - ESALQ/USP, <luiz.henrique2096@itelefonica.com.br>; ${ }^{3}$ Graduando em Engenharia Agronômica - ESALQ/USP, <osofran_esalq@yahoo.com.br>; ${ }^{4}$ Doutorandos em Fitotecnia - ESALQ/USP, <sjpcarvalho@yahoo.com.br>, $<$ mnicolai2009@gmail.com>; ${ }^{5}$ Professor Associado do Dep. de Produção Vegetal - ESALQ/USP, <pjchrist@esalq.usp.br>, Av. Pádua Dias, 11, Caixa Postal 09, 13418-900 Piracicaba-SP. 


\section{INTRODUÇÃO}

Atualmente, o Brasil tem se destacado como o maior produtor mundial de cana-de-açúcar (Saccharum spp.). Apenas na safra de 2007 foram cultivados 6,7 milhões de hectares, com plano de expansão das áreas em $12 \%$ para o ano de 2008. Em termos de produção, foram obtidos 515,8 milhões de toneladas em 2007, com estimativa de produção de mais de 580 milhões de toneladas de cana-de-açúcar em 2008 (IBGE, 2008). Nesse ambiente, um dos pontos críticos no processo produtivo é a interferência negativa imposta pelas plantas daninhas, razão pela qual o adequado manejo tem fundamental importância para a lucratividade desse segmento agricola (Christoffoleti et al., 2006).

Com o advento da colheita de cana-deaçúcar sem queima prévia (cana-crua), têmse observado alterações na flora infestante dos canaviais, como a seleção de espécies com sementes grandes e capacidade de germinar sob a camada de palha, com destaque para Euphorbia heterophylla e espécies do gênero Ipomoea (Pitelli \& Durigan, 2001; Christoffoleti et al., 2007; Cavenaghi et al., 2007). Quantidades de palha de cana-de-açúcar de até 10 e $15 \mathrm{t} \mathrm{ha}^{-1}$ não foram suficientes para afetar a germinação das citadas espécies, o que corrobora o fato de que estas tendem a se manter como problemas em áreas com colheita de cana-de-açúcar sem queima (Martins et al., 1999).

Em geral, as espécies da família Convolvulaceae são plantas nativas da América do Sul, onde são encontradas infestando lavouras, especialmente em culturas anuais de verão das regiões Sul, Sudeste e Centro-Oeste do Brasil. Conhecidas popularmente por corda-de-viola, têm ciclo biológico longo, terminando após a maturação das culturas, o que tende a criar problemas na colheita, sobretudo em cana-de-açúcar, pois seus ramos se fixam aos colmos da cultura (Kissmann \& Groth, 1999; Lorenzi, 2000). Azania et al. (2002) acrescentam ainda que as convolvuláceas, principalmente aquelas pertencentes aos gêneros Ipomoea e Merremia, além de competirem com a cana-de-açúcar em áreas de colheita sem queima prévia, interferem nas práticas culturais, como a colheita mecanizada, reduzindo sua eficiência.
Na cultura da cana-de-açúcar, o manejo das plantas daninhas baseia-se no controle químico, cuja principal forma é a aplicação de herbicidas em pré-emergência das plantas daninhas e da cultura (Christoffoleti \& LópezOvejero, 2005). Ainda, em áreas onde as plantas daninhas devem ser controladas por longos períodos, como é o caso da cana-de-açúcar, há necessidade de utilização de herbicidas com ação residual prolongada (Velini \& Negrisoli, 2000). Entre as diversas opções de herbicidas registrados para a cultura da canade-açúcar encontram-se o sulfentrazone e o amicarbazone (Rodrigues \& Almeida, 2005), que são considerados opções para manejo de espécies da família Convolvulaceae. Nesse sentido, informações que relacionem a dose aplicada e a eficácia de herbicidas são importantes e facilitam a tomada de decisão em um sistema de produção, de forma a obter controles satisfatórios com possivel economia de herbicida e redução de custos.

Comumente, espécies do mesmo gênero ou familia de plantas não respondem de maneira uniforme à aplicação de herbicidas, caracterizando a suscetibilidade diferencial das espécies (Mathis \& Oliver, 1980; Christoffoleti et al., 2006; Carvalho et al., 2006). Assim, este trabalho foi desenvolvido com o objetivo de avaliar a suscetibilidade de três espécies de plantas daninhas da família Convolvulaceae (I. quamoclit, I. triloba e M. cissoides) aos herbicidas sulfentrazone e amicarbazone, quando aplicados em pré-emergência.

\section{MATERIAL E MÉTODOS}

Dois experimentos foram desenvolvidos em área pertencente à Usina São Martinho $\mathrm{S} / \mathrm{A}$, no município de Iracemápolis - SP, no período compreendido entre dezembro de 2007 e março de 2008. O solo foi previamente preparado com gradagem intermediária $(0,20 \mathrm{~m})$, sendo mantido sem cultura durante todo o período. Em um dos experimentos, estudou-se a suscetibilidade de três espécies da família Convolvulaceae ao herbicida sulfentrazone; no outro, aplicou-se amicarbazone. O solo da área experimental foi classificado como Latossolo Vermelho distrófico de textura argilosa (58\% de argila, 23\% de areia e 19\% de silte), cuja análise química está apresentada na Tabela 1. 
Tabela 1 - Propriedades químicas do solo da área experimental. Iracemápolis-SP, 2008

\begin{tabular}{|c|c|c|c|c|c|c|c|c|c|c|c|c|}
\hline \multicolumn{2}{|c|}{$\mathrm{pH}$} & M.O. & P resina & $\mathrm{K}$ & $\mathrm{Ca}$ & $\mathrm{Mg}$ & $\mathrm{Al}$ & $\mathrm{S}$ & $\mathrm{CTC}$ & $\mathrm{V}$ & $\mathrm{M}$ \\
\hline$(\mathrm{KCl})$ & $\left(\mathrm{H}_{2} \mathrm{O}\right)$ & $\left(\mathrm{g} \mathrm{dm}^{-3}\right)$ & $\left(\mathrm{mg} \mathrm{dm}^{-3}\right)$ & \multicolumn{7}{|c|}{$\left(\mathrm{mmol}_{\mathrm{c}} \mathrm{dm}^{-3}\right)$} & & $(\%)$ \\
\hline 4,0 & 5,0 & 27 & 11 & 3,3 & 16 & 10 & 6,4 & 29,3 & 100,9 & 29,0 & 17,9 \\
\hline
\end{tabular}

Em ambos os experimentos, o delineamento experimental adotado foi blocos ao acaso com quatro repetições. Os tratamentos foram alocados em campo, segundo esquema de parcelas subdivididas, em que no âmbito das parcelas foram aplicadas as oito doses dos herbicidas, enquanto nas subparcelas foram alocadas três espécies de plantas daninhas (Merremia cissoides, Ipomoea triloba e Ipomoea quamoclit). Cada parcela contou com área de $1,5 \times 2 \mathrm{~m}$, onde foram instalados três sulcos de semeadura paralelos, espaçados de $0,5 \mathrm{~m}$ (subparcelas), com aproximadamente $20 \mathrm{~mm}$ de profundidade. As plantas daninhas foram semeadas no dia 23 de dezembro de 2007. As sementes foram distribuídas almejando população final de 25 plantas por metro linear, o que correspondeu aos seguintes volumes de semente: 2,0 mL de sementes de $M$. cissoides (primeiro sulco); 1,0 mL de $I$. triloba (segundo sulco); e 1,5 mL de I. quamoclit (terceiro sulco).

As doses utilizadas foram $8 \mathrm{D}, 4 \mathrm{D}, 2 \mathrm{D}, \mathrm{D}$, $1 / 2 \mathrm{D}, 1 / 4 \mathrm{D}, 1 / 8 \mathrm{D}$ e testemunha sem aplicação, sendo $\mathrm{D}$ a dose recomendada de sulfentrazone $\left(600 \mathrm{~g} \mathrm{ha}^{-1}\right)$ ou de amicarbazone (980 $\left.\mathrm{g} \mathrm{ha}^{-1}\right)$. Todas as aplicações foram realizadas logo após a semeadura, com auxílio de pulverizador costal pressurizado por $\mathrm{CO}_{2}$, acoplado a barra com quatro pontas de pulverização tipo leque, espaçadas de $0,5 \mathrm{~m}$, com jato plano, modelo XR 110.02, calibrado para volume de calda correspondente a $200 \mathrm{~L} \mathrm{ha}^{-1}$. No momento da aplicação, as condições meteorológicas estimadas foram: UR (\%) de $59 \%$, T $\left({ }^{\circ} \mathrm{C}\right)$ de $29{ }^{\circ} \mathrm{C}$ e vento de $1,5 \mathrm{~km} \mathrm{~h}^{-1}$. Os dados de temperatura e precipitação registrados para o periodo de condução do experimento estão apresentados na Figura 1.

Foram realizadas avaliações visuais de controle percentual aos 15, 30, 45 e 60 dias após aplicação (DAA). Em ambos os experimentos, as avaliações foram baseadas em escala com controles extremos de zero (ausência de controle) e $100 \%$ (controle absoluto - ausência de infestação). Os dados foram inicialmente submetidos à aplicação do teste F na análise da variância, com auxílio do programa estatístico Sisvar 5.0 (Ferreira, 2000). Quando significativos, os niveis qualitativos (espécies) foram comparados pelo teste de Tukey a 5\% de significância. Os niveis do fator herbicida (doses) foram analisados pelo programa estatístico TableCurve 2D v.5.01, com o emprego de regressões não lineares do tipo log-logístico, segundo o modelo proposto por Streibig (1988):

$$
y=\frac{a}{\left[1+\left(\frac{x}{b}\right)^{c}\right]}
$$

em que: $y$ é a porcentagem de controle; $x$, a dose do herbicida em gi.a. ha ${ }^{-1}$, e $a, b$ e $c$, parâmetros estimados da equação, de tal forma que $a$ é a amplitude existente entre o ponto máximo e o ponto mínimo da variável, $b$ corresponde à dose necessária para a ocorrência de $50 \%$ de resposta da variável e cé a declividade da curva ao redor de b.

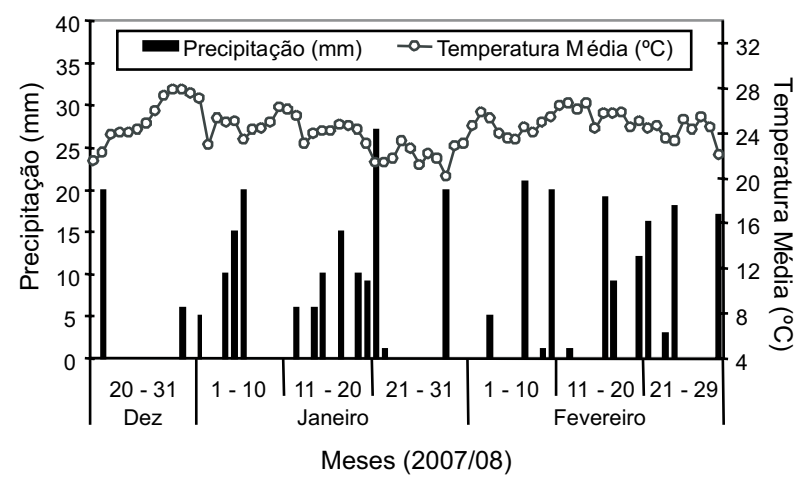

Figura 1 - Temperatura média estimada $\left({ }^{\circ} \mathrm{C}\right)$ e precipitações $(\mathrm{mm})$ diárias registradas para local e período de condução dos experimentos em campo. Iracemápolis-SP, 2008. 
O modelo logístico apresenta vantagens, uma vez que um dos termos integrantes da equação $(b)$ é a estimativa do valor de $\mathrm{C}_{50}$ (Christoffoleti, 2002). $\mathrm{C}_{50}$ equivale à dose do herbicida em gramas de ingrediente ativo por hectare que proporciona o valor de $50 \%$ de controle (Christoffoleti, 2002; Christoffoleti \& López-Ovejero, 2004). Embora um dos parâmetros do modelo logístico (b) seja uma estimativa do valor de $\mathrm{C}_{50}$, optou-se também por realizar seu cálculo matemático por meio da equação inversa, com base na discussão proposta por Carvalho et al. (2005). Da mesma forma foram calculados os valores de $\mathrm{C}_{80}$, visto que este é o nível mínimo de controle considerado satisfatório pela legislação em vigor.

\section{RESULTADOS E DISCUSSÃO}

Com a aplicação do teste $\mathrm{F}$ na análise da variância, constatou-se significância do fator espécie de planta daninha apenas para algumas das datas de avaliação, em ambos os experimentos. Comportamento semelhante foi observado para a significância da interação de espécies de plantas daninhas com doses de herbicida. Assim, para maior compreensão dos procedimentos estatísticos de comparação de espécies e análise por regressões, optou-se por apresentar o quadro da análise da variância dos dois experimentos, em formato resumido (Tabela 2). O quadro da análise da variância foi elaborado de acordo com o modelo de parcelas subdivididas, com oito doses do herbicida (efeito principal; GL $=7$ ) e três espécies daninhas (efeito secundário; $G L=2$ ). A ausência de interações $(G L=14)$ indica que o comportamento das espécies foi constante para todas as doses de herbicida. Essa condição ficou evidente no experimento desenvolvido com o herbicida sulfentrazone, quando avaliado aos 30 e 45 DAA. Foram observados efeitos isolados de doses e espécies, que justificaram a aplicação do teste de Tukey, caracterizando a seguinte ordem de suscetibilidade: I. quamoclit $\geq M$. cissoides $\geq I$. triloba (Tabela 3 ).

No estudo com o amicarbazone, aos 15 DAA, também se observaram apenas efeitos isolados de doses e espécies, sem interação, em que a ordem de suscetibilidade foi: I. quamoclit $>M$. cissoides $=I$. triloba. Por outro lado, aos 45 DAA, a significância foi obtida somente para as doses de amicarbazone, quando a aplicação de teste de comparações múltiplas não é necessária, justificando apenas a apresentação dos dados brutos (Tabela 3). Ressalta-se que os controles apresentados na Tabela 3 são relativos à média de todos os tratamentos, incluindo as testemunhas, o que

Tabela 2 - Resumo do quadro da análise da variância para as diferentes avaliações de controle de espécies de corda-deviola, quando relacionadas às fontes de variação do experimento ${ }^{1 /}$, bem como à interação destas. IracemápolisSP, 2008

\begin{tabular}{|c|c|c|c|c|}
\hline Variável & Fonte de variação & $\mathrm{GL}^{2} /$ & $\mathrm{F}$ & $\operatorname{Pr}>\mathrm{Fc}$ \\
\hline \multicolumn{5}{|c|}{ Sulfentrazone } \\
\hline \multirow{3}{*}{ Controle aos $15 \mathrm{DAA}^{\underline{3}}$} & Espécies (E) & 2 & $10,415 * *$ & $<0,001$ \\
\hline & Doses (D) & 7 & $33,600^{* *}$ & $<0,001$ \\
\hline & Interação (E*D) & 14 & $3,337 * *$ & 0,001 \\
\hline \multirow{3}{*}{ Controle aos 30 DAA } & Espécies (E) & 2 & $4,437 *$ & 0,017 \\
\hline & $\begin{array}{l}\text { Doses (D) } \\
\end{array}$ & 7 & $19,122 * *$ & $<0,001$ \\
\hline & Interação (E*D) & 14 & $1,586^{\mathrm{NS}}$ & 0,118 \\
\hline \multirow{3}{*}{ Controle aos 45 DAA } & Espécies (E) & 2 & $4,544^{*}$ & 0,016 \\
\hline & Doses (D) & 7 & $17,781 * *$ & $<0,001$ \\
\hline & Interação (E*D) & 14 & $1,380^{\mathrm{NS}}$ & 0,199 \\
\hline \multirow{3}{*}{ Controle aos 60 DAA } & Espécies (E) & 2 & $5,525 * *$ & 0,007 \\
\hline & Doses (D) & 7 & $18,820 * *$ & $<0,001$ \\
\hline & Interação (E*D) & 14 & $1,927^{*}$ & 0,047 \\
\hline \multicolumn{5}{|c|}{ Amicarbazone } \\
\hline \multirow{3}{*}{ Controle aos 15 DAA } & Espécies (E) & 2 & $23,309^{* *}$ & $<0,001$ \\
\hline & Doses (D) & 7 & $9,216^{* *}$ & $<0,001$ \\
\hline & Interação (E*D) & 14 & $1,834^{\mathrm{NS}}$ & 0,061 \\
\hline \multirow{3}{*}{ Controle aos 30 DAA } & Espécies (E) & 2 & $1,470^{\mathrm{NS}}$ & 0,240 \\
\hline & Doses (D) & 7 & $59,714^{* *}$ & $<0,001$ \\
\hline & Interação (E*D) & 14 & $2,007^{*}$ & 0,038 \\
\hline \multirow{3}{*}{ Controle aos 45 DAA } & Espécies (E) & 2 & $2,140^{\mathrm{NS}}$ & 0,129 \\
\hline & Doses (D) & 7 & $42,391 * *$ & $<0,001$ \\
\hline & Interação (E*D) & 14 & $1,602^{\mathrm{NS}}$ & 0,113 \\
\hline \multirow{3}{*}{ Controle aos 60 DAA } & Espécies (E) & 2 & $2,059^{\mathrm{NS}}$ & 0,134 \\
\hline & Doses (D) & 7 & $42,860 * *$ & $<0,001$ \\
\hline & Interação (E*D) & 14 & $1,991^{*}$ & 0,039 \\
\hline
\end{tabular}

${ }^{1 /}$ Delineamento em parcelas subdivididas; ${ }^{2 /} \mathrm{GL}$ - graus de liberdade; 3/ dias após aplicação; * significativo a $5 \%$ de probabilidade; ** significativo a $1 \%$ de probabilidade; ${ }^{N S}$ - não significativo.

Tabela 3 - Controle ${ }^{1 /}$ de três espécies de corda-de-viola quando submetidas à aplicação dos herbicidas sulfentrazone e amicarbazone. Iracemápolis-SP, 2008

\begin{tabular}{|l|c|c|c|c|}
\hline \multirow{2}{*}{ Espécie } & \multicolumn{2}{|c|}{ Sulfentrazone } & \multicolumn{2}{c|}{ Amicarbazone } \\
\cline { 2 - 5 } & $30 \mathrm{DAA}^{2 /}$ & $45 \mathrm{DAA}$ & $15 \mathrm{DAA}$ & $45 \mathrm{DAA}^{\frac{3}{2}}$ \\
\hline Merremia cissoides & $75,94 \mathrm{AB}$ & $75,16 \mathrm{AB}$ & $56,88 \mathrm{~B}$ & 79,81 \\
\hline Ipomoea triloba & $71,09 \mathrm{~B}$ & $71,34 \mathrm{~B}$ & $54,84 \mathrm{~B}$ & 82,91 \\
\hline Ipomoea quamoclit & $81,25 \mathrm{~A}$ & $80,25 \mathrm{~A}$ & $66,88 \mathrm{~A}$ & 82,38 \\
\hline DMS & 8,25 & 7,17 & 4,56 & - \\
\hline
\end{tabular}

${ }^{1 /}$ Dados referentes à media de todas as doses, incluindo a testemunha sem aplicação; 2/ Dias após aplicação; ${ }^{3 /}$ Sem diferença pelo teste $\mathrm{F}$ a 5\% de significância; médias seguidas por letras maiúsculas iguais, na coluna, não diferem entre si pelo teste de Tukey a 5\% de significância. 
reduz o valor numérico e valida apenas a comparação das espécies e não a análise de eficácia dos herbicidas.

$\mathrm{O}$ efeito de doses dos herbicidas foi evidente em todas as avaliações, resultando no estudo de regressões com o modelo logístico. Na Tabela 4 estão apresentados os parâmetros do modelo ajustados para os controles obtidos com a aplicação das diferentes doses de sulfentrazone ou amicarbazone sobre as três espécies de plantas daninhas. Com esses dados, podem-se calcular matematicamente quaisquer niveis de controle, inclusive os valores de $\mathrm{C}_{50}$ e $_{80}$ (Carvalho et al., 2005), que caracterizaram os niveis de suscetibilidade das espécies aos herbicidas, bem como auxiliaram na elaboração dos gráficos apresentados nas Figuras 2 e 3.

A dose recomendada do herbicida sulfentrazone proporcionou excelente controle de todas as plantas daninhas já na primeira avaliação, realizada aos $15 \mathrm{DAA}$, que se manteve até o final do experimento (Figura 2). $\mathrm{O}$ cálculo de $\mathrm{C}_{80}$ resultou em doses sempre inferiores à dose recomendada do produto (600 g i.a. ha-1), o que realça a elevada eficácia da molécula para controle das três plantas daninhas (Tabela 4). Nesse sentido, a análise conjunta da Figura 2 e das Tabelas 3 e 4 caracteriza a suscetibilidade diferencial das espécies, em que $I$. triloba foi a mais tolerante, com $\mathrm{C}_{80}$ da ordem de $310 \mathrm{~g} \mathrm{ha}^{-1}$. Em geral, a ordem de suscetibilidade das plantas daninhas ao sulfentrazone foi: $I$. quamoclit $\geq M$. cissoides $\geq$ I. triloba (Tabela 4).

Em plantas, o sulfentrazone atua na rota de sintese de clorofilas e citocromos, inibindo a protoporfirinogênio oxidase (PROTOX), o que resulta em acúmulo de protoporfirinogênio no cloroplasto. Em altas concentrações, há difusão do protoporfirinogênio para o citoplasma, onde é rapidamente convertido em protoporfirina-IX, a qual é um pigmento fotodinâmico que, quando em presença de luz e oxigênio molecular, dá origem ao oxigênio 'singlet' $\left(\mathrm{O}^{-}\right)$. Esse radical livre, altamente reativo, provoca a peroxidação dos lipídeos das membranas, levando a célula à morte (Carvalho \& López-Ovejero, 2008). Essas características do mecanismo de ação auxiliam na explicação da rápida morte das plantas, o que justifica os elevados valores de controle

Tabela 4 - Parâmetros do modelo logístico ${ }^{1 /}$, coeficiente de determinação $\left(\mathrm{R}^{2}\right), \mathrm{C}_{50}$ e $_{80}$ para controle de três espécies de corda-deviola, após aplicação de diferentes doses de sulfentrazone e amicarbazone. Iracemápolis-SP, 2008

\begin{tabular}{|c|c|c|c|c|c|c|c|}
\hline \multirow{2}{*}{ Avaliação } & \multirow{2}{*}{ Espécie } & \multicolumn{3}{|c|}{ Parâmetro } & \multirow{2}{*}{$\mathrm{R}^{2}$} & \multicolumn{2}{|c|}{$\mathrm{C}$} \\
\hline & & $a$ & $b$ & $c$ & & 50 & 80 \\
\hline \multicolumn{8}{|c|}{ Sulfentrazone } \\
\hline \multirow{3}{*}{$15 \mathrm{DAA}^{2 /}$} & Merremia cissoides & 94,593 & 115,295 & $-2,332$ & 0,962 & 121,09 & 239,16 \\
\hline & Ipomoea triloba & 101,381 & 171,804 & $-2,244$ & 0,997 & 169,73 & 309,32 \\
\hline & Ipomoea quamoclit & 98,908 & 73,140 & $-2,383$ & 0,990 & 73,82 & 133,98 \\
\hline 30 DAA & Geral & 100,125 & 90,517 & $-2,303$ & 0,999 & 90,42 & 164,81 \\
\hline 45 DAA & Geral & 100,038 & 89,932 & $-2,056$ & 0,998 & 89,90 & 176,34 \\
\hline \multirow{3}{*}{$60 \mathrm{DAA}$} & Merremia cissoides & 100,425 & 79,533 & $-1,601$ & 0,998 & 79,11 & 186,59 \\
\hline & Ipomoea triloba & 100,946 & 126,369 & $-2,073$ & 0,998 & 125,23 & 241,21 \\
\hline & Ipomoea quamoclit & 100,436 & 65,161 & $-1,968$ & 0,997 & 64,87 & 130,36 \\
\hline \multicolumn{8}{|c|}{ Amicarbazone } \\
\hline $15 \mathrm{DAA}$ & Geral & 83,301 & 175,115 & $-1,532$ & 0,997 & 228,32 & $1.402,84$ \\
\hline \multirow{3}{*}{30 DAA } & Merremia cissoides & 100,653 & 103,019 & $-2,378$ & 0,997 & 102,46 & 182,07 \\
\hline & Ipomoea triloba & 100,631 & 78,922 & $-2,483$ & 0,996 & 78,52 & 136,22 \\
\hline & Ipomoea quamoclit & 99,144 & 71,802 & $-2,071$ & 0,996 & 72,40 & 143,23 \\
\hline $45 \mathrm{DAA}$ & Geral & 100,430 & 93,780 & $-2,274$ & 0,998 & 93,43 & 170,93 \\
\hline \multirow{3}{*}{$60 \mathrm{DAA}$} & Merremia cissoides & 100,648 & 113,114 & $-2,447$ & 0,998 & 112,52 & 196,74 \\
\hline & Ipomoea triloba & 100,765 & 94,736 & $-2,378$ & 0,994 & 94,13 & 167,05 \\
\hline & Ipomoea quamoclit & 100,274 & 89,650 & $-2,145$ & 0,999 & 89,42 & 170,01 \\
\hline
\end{tabular}

1/ Modelo: $\mathrm{y}=\left(\mathrm{a} /\left(1+(\mathrm{x} / \mathrm{b})^{\mathrm{c}}\right)\right)$; $\stackrel{2}{\text { ? }} \mathrm{DAA}-$ dias após aplicação. 
observados já na avaliação realizada aos 15 DAA (Figura 2).

No solo, a atividade residual do sulfentrazone é longa, podendo, inclusive, provocar problemas às culturas instaladas em sucessão (Blanco \& Velini, 2005). Vivian et al. (2006), trabalhando com Argissolo VermelhoAmarelo em avaliações sempre superiores a 180 DAA, observaram que a maioria dos resíduos de sulfentrazone foi detectada em profundidade de $0-10 \mathrm{~cm}$, sendo pouco significativa a lixiviação no solo. Rossi et al. (2005) e Bachega et al. (2009) também detectaram baixa mobilidade do sulfentrazone no perfil do solo, permanecendo na camada superficial, independentemente da precipitação. Estes autores avaliaram a persistência do herbicida em um Latossolo Vermelho - mesma classificação do solo utilizado neste trabalho. A baixa mobilidade do sulfentrazone, principalmente em solos com maior teor de argila, aliada à suscetibilidade das espécies ao produto, auxiliam na compreensão da elevada eficácia avaliada aos 60 DAA, mesmo após ocorrência de mais de $200 \mathrm{~mm}$ de chuva (Figuras 1 e 2).

Para a cultura da cana-de-açúcar, diversos estudos têm destacado a grande importância, ocorrência e dificuldade de controle da familia Convolvulaceae, com especial destaque para I. triloba (Christoffoleti et al., 2006; Kuva et al., 2007; Monquero et al., 2008). Contudo, vale destacar que em muitos dos trabalhos se estudou espécie discriminada por I. grandifolia. Atualmente, considera-se I. triloba o nome científico mais correto para a espécie, embora ambos sejam sinonimias (Kissmann $\&$ Groth, 1999; Lorenzi, 2006). Nesse sentido, Christoffoleti et al. (2006) compararam a suscetibilidade de quatro espécies de Ipomoea ao herbicida carfentrazone, também inibidor da PROTOX, em casa de vegetação e observaram diferenças interespecíficas, em que a ordem de suscetibilidade foi: I. hederifolia $\geq$ I. quamoclit > I. nil > I. grandifolia, o que está em concordância com os dados observados neste trabalho.
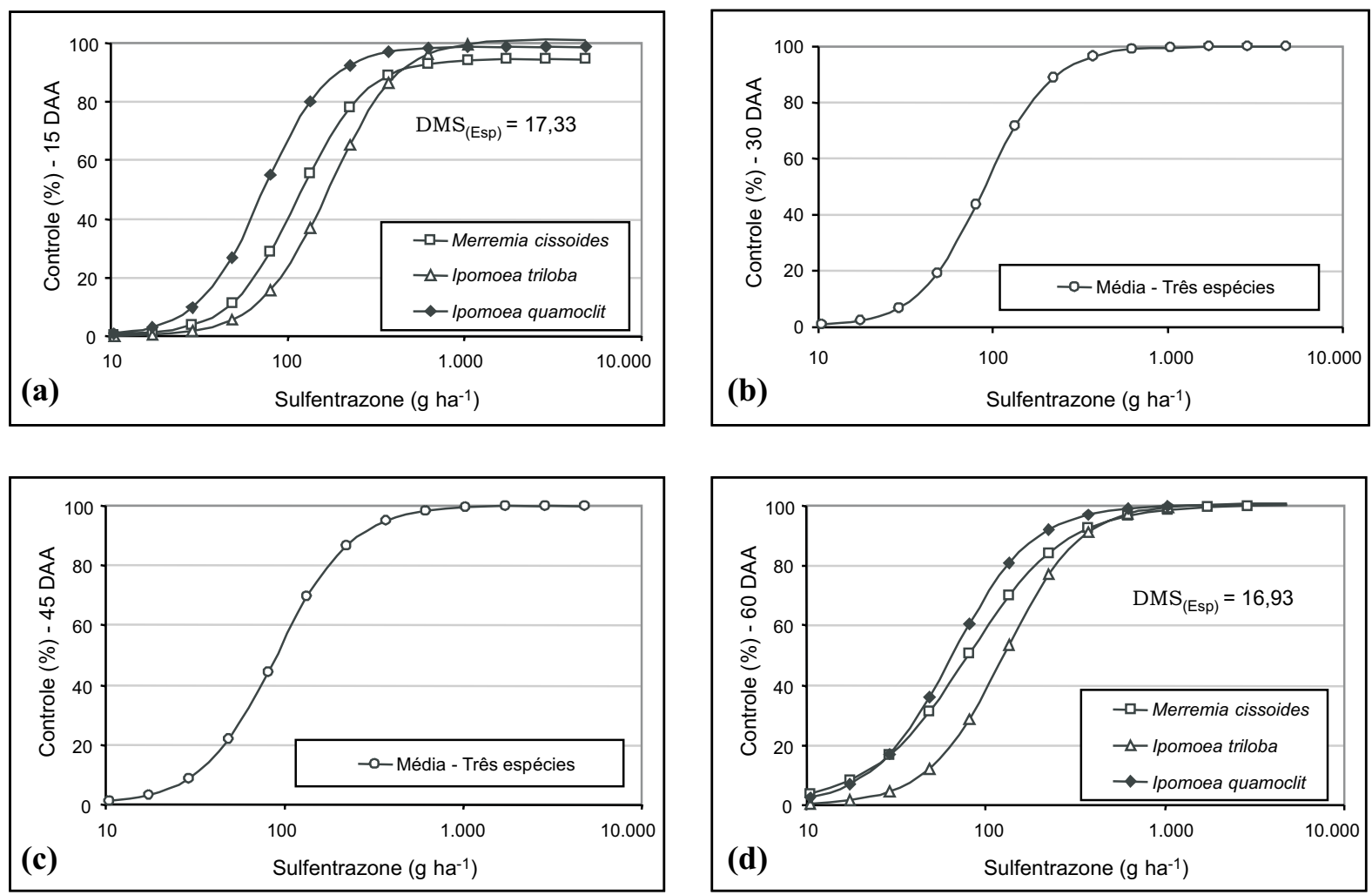

Figura 2 - Controle de espécies de corda-de-viola com o herbicida sulfentrazone, avaliado aos 15 (a), 30 (b), 45 (c) e 60 (d) dias após aplicação (DAA). Iracemápolis, 2008. 
Com relação ao sulfentrazone, Negrisoli et al. (2004) também observaram elevada eficácia desse herbicida em I. grandifolia. Em outro trabalho, I. grandifolia foi controlada aos 14 DAA (>91\%) pelos herbicidas glyphosate, carfentrazone-ethyl, sulfentrazone e flumioxazin, aplicados isoladamente (Monquero et al., 2001). Trabalhando com o imazapic, herbicida alternativo e também de longa atividade residual, Francisco et al. (2007) compararam a suscetibilidade de I. triloba e E. heterophylla. Concluíram que o imazapic foi eficaz em ambas as espécies, porém foi necessário maior dose para redução de fitomassa seca de $I$. triloba, caracterizando esta espécie como menos suscetivel que $E$. heterophylla.

No segundo experimento, o herbicida amicarbazone também controlou adequadamente as três espécies de plantas daninhas, exceto aos 15 DAA, quando os controles máximos se estabilizaram em $80 \%$ (Figura 3). Supõe-se que o menor controle observado aos 15 DAA esteja relacionado com o mecanismo de ação do herbicida amicarbazone, do tipo inibidor do fotossistema II. Nesse caso, há necessidade de emergência e estabelecimento das plântulas até o momento de início de atividade fotossintética, quando a eficácia do herbicida se manifesta. Ainda, a ausência de chuva por uma semana após a semeadura das espécies pode ter contribuído para menores controles iniciais (Figura 1), em razão da menor percolação do produto nos centímetros superficiais do solo. Nesse sentido, Negrisoli et al. (2007) e Toledo et al. (2009) também constataram elevada eficácia do amicarbazone para controle de I. grandifolia, porém ressaltaram que a lixiviação pode ser um processo fundamental para a apropriada absorção e eficácia do herbicida, sobretudo em áreas com aplicação sobre a palhada de cana-de-açúcar.

Nas avaliações realizadas aos 30, 45 e 60 DAS, os valores de $\mathrm{C}_{80}$ calculados para aplicação de amicarbazone em pré-emergência das três espécies mantiveram-se sempre inferiores a $200 \mathrm{~g} \mathrm{ha}^{-1}$ (Tabela 4) e, portanto,
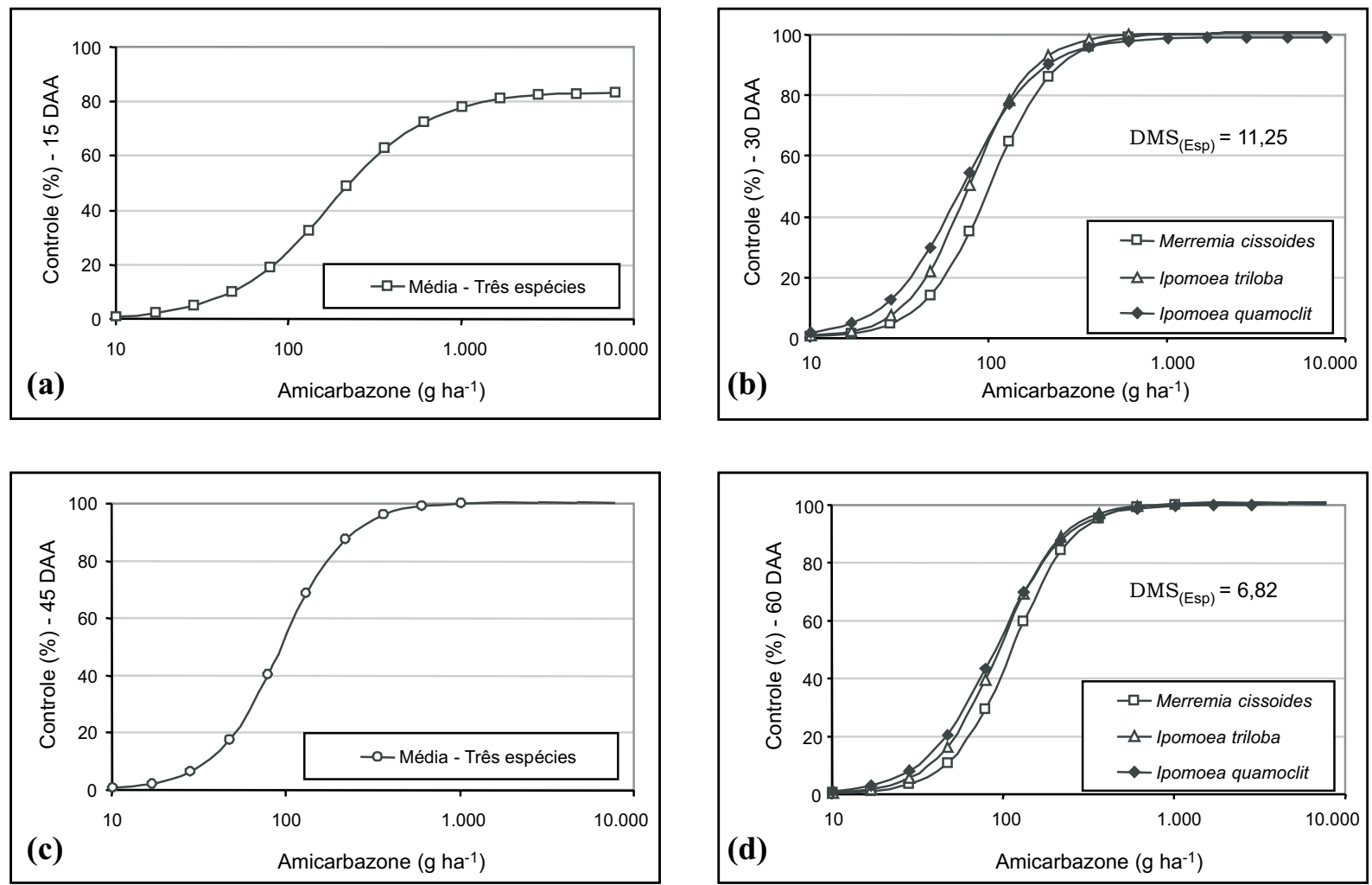

Figura 3 - Controle de espécies de corda-de-viola com o herbicida amicarbazone, avaliado aos 15 (a), 30 (b), 45 (c) e 60 (d) dias após aplicação (DAA). Iracemápolis, 2008. 
bastante diferenciados da dose recomendada de amicarbazone $\left(980 \mathrm{~g} \mathrm{ha}^{-1}\right)$. Também neste experimento, a análise conjunta da Figura 3 e das Tabelas 3 e 4 caracteriza a suscetibilidade diferencial das espécies, que ocorreu em menor grau que aquela observada para sulfentrazone. A interação dose-espécie foi observada aos 30 e 60 DAA, cuja ordem de suscetibilidade foi: I. quamoclit $\geq$ I. triloba $\geq$ $M$. cissoides (Figura 3). Dessa forma, o amicarbazone também pode ser caracterizado como um herbicida eficaz para o manejo dessas espécies daninhas.

O amicarbazone tem recomendação para aplicação tanto em pré como em pós-emergência da cultura da cana-de-açúcar e das plantas daninhas. Quando aplicado ao solo, é absorvido pelas raízes e translocado em rota apoplástica, via xilema, com o fluxo transpiratório das plantas até as folhas. Quando aplicado em pós-emergência, possui ação basicamente de contato. Esse herbicida inibe a fotossintese das plantas daninhas, atuando na reação de Hill (fotossistema II), interrompendo o transporte de elétrons e paralisando a fixação de $\mathrm{CO}_{2}$ e a produção de ATP e $\mathrm{NADPH}_{2}$, os quais são elementos essenciais ao crescimento das plantas. A morte das plantas, entretanto, pode ocorrer devido a outros processos, como a peroxidação de lipídeos e proteínas, promovendo a destruição das membranas e perda de clorofila (Toledo et al., 2009; Cavenaghi et al., 2007).

Estudos demonstraram diferenças de suscetibilidade de espécies de Ipomoea também ao herbicida bentazon, outro inibidor do fotossistema II (McClelland et al., 1978; Mathis \& Oliver, 1980); contudo, a suscetibilidade diferencial de espécies não se restringe ao gênero Ipomoea. Já foram identificadas diferenças interespecíficas de suscetibilidade do gênero Digitaria ao herbicida diuron (Dias et al., 2003); de espécies de Bidens aos herbicidas chlorimuron-ethyl e imazethapyr (López-Ovejero et al., 2006); de espécies de Amaranthus aos herbicidas trifloxysulfuronsodium e chlorimuron-ethyl (Carvalho et al., 2006); e de espécies de Commelina aos herbicidas glyphosate e carfentrazone (Rocha et al., 2007).

A diferença de suscetibilidade de espécies de plantas daninhas a herbicidas pode estar relacionada com a afinidade enzimática das moléculas; com a absorção, translocação ou exclusão diferencial dos herbicidas; ou mesmo com rotas de detoxificação metabólica (Carvalho et al., 2006). Entretanto, mais estudos devem ser conduzidos para esclarecer quais fatores têm participação na resposta diferencial de controle das espécies de plantas daninhas da familia Convolvulaceae. Assim, conclui-se que as doses recomendadas de ambos os herbicidas foram eficazes para controlar as três plantas daninhas nas avaliações realizadas até os 60 dias após aplicação. Observouse suscetibilidade diferencial entre as espécies estudadas, em que I. quamoclit foi a espécie mais sensivel. As ordens de suscetibilidade das espécies aos herbicidas foram: I. quamoclit $\geq M$. cissoides $\geq I$. triloba para o sulfentrazone; e I. quamoclit $\geq I$. triloba $\geq$ $M$. cissoides para o amicarbazone. Os niveis de controle obtidos indicam a viabilidade de aplicação de sulfentrazone e amicarbazone em pré-emergência para controle dessas espécies de plantas daninhas da família Convolvulaceae.

\section{LITERATURA CITADA}

AZANIA, A. A. P. M. et al. Interferência da palhada da cana-de-açúcar na emergência de espécies de plantas daninhas da família Convolvulaceae. Planta Daninha, v. 20, n. 2, p. 207-212, 2002.

BACHEGA, T. F. et al. Lixiviação de sulfentrazone e amicarbazone em coluna de solo com adição de óleo mineral. Planta Daninha, v. 27, n. 2, p. 363-370, 2009.

BLANCO, F. M. G.; VELINI, E. D. Persistência do herbicida sulfentrazone em solo cultivado com soja e seu efeito em culturas sucedâneas. Planta Daninha, v. 23, n. 4, p. 693-700, 2005.

CARVALHO, S. J. P.; LÓPEZ-OVEJERO, R. F. Resistência de plantas daninhas aos herbicidas inibidores da PROTOX (Grupo E). In: CHRISTOFFOLETI, P. J. (Coord.). Aspectos de resistência de plantas daninhas a herbicidas. Piracicaba: HRAC-BR, 2008. p. 69-77.

CARVALHO, S. J. P. et al. Suscetibilidade diferencial de plantas daninhas do gênero Amaranthus aos herbicidas trifloxysulfuron-sodium e chlorimuron-ethyl. Planta Daninha, v. 24, n. 3, p. 541-548, 2006.

CARVALHO, S. J. P. et al. Curvas de dose-resposta para avaliação do controle de fluxos de emergência de plantas daninhas pelo herbicida imazapic. Planta Daninha, v. 23, n. 3, p. 535-542, 2005. 
CAVENAGHI, A. L. et al. Dinâmica do herbicida amicarbazone (Dinamic) aplicado sobre palha de cana-deaçúcar (Saccharum officinarum). Planta Daninha, v. 25, n. 4, p. 831-837, 2007.

CHRISTOFFOLETI, P. J. et al. Conservation of natural resources in Brazilian agriculture: implications on weed biology and management. Crop Protec., v. 26, n. 3, p. 383-389, 2007.

CHRISTOFFOLETI, P. J. et al. Carfentrazone-ethyl aplicado em pós-emergência para o controle de Ipomoea spp. e Commelina benghalensis na cultura da cana-de-açúcar. Planta Daninha, v. 24, n. 1, p. 83-90, 2006

CHRISTOFFOLETI, P. J.; LÓPEZ-OVEJERO, R. F. Dinâmica de herbicidas aplicados ao solo na cultura da cana-de-açúcar. Piracicaba: Edição dos Autores, 2005. 49 p

CHRISTOFFOLETI, P. J.; LÓPEZ-OVEJERO, R. F. Definições e situação da resistência de plantas daninhas aos herbicidas no Brasil e no Mundo. In: CHRISTOFFOLETI, P. J. (Coord.). Aspectos de resistência de plantas daninhas a herbicidas. 2.ed. Campinas: HRAC-BR, 2004. p. 3-22.

CHRISTOFFOLETI, P. J. Curvas de dose-resposta de biótipos resistente e suscetível de Bidens pilosa L. aos herbicidas inibidores da ALS. Sci. Agric., v. 59, n. 3, p. 513-519, 2002.

DIAS, N. M. P. et al. Absorção e translocação do herbicida diuron por espécies suscetível e tolerante de capim-colchão (Digitaria spp.). Planta Daninha, v. 21, n. 2, p. 293-300, 2003.

FERREIRA, D. F. Análises estatísticas por meio do Sisvar para Windows versão 4.0. In : REUNIÃO ANUAL DA REGIÃO BRASILEIRA DA SOCIEDADE

INTERNACIONAL DE BIOMETRIA, 45., 2000, São Carlos. Anais... São Carlos: UFSCar, 2000. p. 255-258.

FRANCISCO, M. O. et al. Curvas de dose-resposta para avaliação do controle de Ipomoea triloba e Euphorbia heterophylla com o herbicida imazapic. STAB, v. 25 , n. 5 , p. $38-42,2007$.

INSTITUTO BRASILEIRO DE GEOGRAFIA E ESTATÍSTICA - IBGE. Disponível em: http://www.ibge. gov.br/home/estatistica/indicadores/agropecuaria/lspa/ default.shtm. Acesso em: 7 de julho de 2008

KISSMANN, K. G.; GROTH, D. Plantas infestantes e nocivas. 2.ed. São Paulo: BASF, 1999. v. 2. 978 p.

KUVA, M. A. et al. Fitossociologia de comunidades de plantas daninhas em agroecossistema cana-crua. Planta Daninha, v. 25, n. 3, p. 501-511, 2007.
LÓPEZ-OVEJERO, R. F. et al. Resistance and differential susceptibility of Bidens pilosa and B. subalternans biotypes to ALS-inhibiting herbicides. Sci. Agric., v. 63, n. 2, p. $139-145,2006$.

LORENZI, H. Manual de identificação e controle de plantas daninhas: plantio direto e convencional. 6.ed. Nova Odessa: Instituto Plantarum, 2006. 339 p.

LORENZI, H. Plantas daninhas do Brasil: terrestres, aquáticas, parasitas e tóxicas. 3.ed. Nova Odessa: Instituto Plantarum, 2000. $608 \mathrm{p}$

MARTINS, D. et al. Emergência em campo de dicotiledôneas infestantes em solo coberto com palha de cana-de-açúcar. Planta Daninha, v. 17, n. 1, p. 151-161, 1999.

MATHIS, W. D.; OLIVER, L. R. Control of six morningglory (Ipomoea) species in soybeans (Glycine max). Weed Sci., v. 28 , n. 4 , p. $409-415,1980$

McCLELLAND, M. R. et al. Responses of six morningglory (Ipomoea) species to bentazon. Weed Sci., v. 26, n. 5, p. 459-464, 1978.

MONQUERO, P. A. et al. Mapas de infestação de plantas daninhas em diferentes sistemas de colheita de cana-de-açúcar Planta Daninha, v. 26, n. 1, p. 47-55, 2008

MONQUERO, P. A.; CHRISTOFFOLETI, P. J.; SANTOS, C. T. Glyphosate em mistura com herbicidas alternativos para o manejo das plantas daninhas. Planta Daninha, v. 19, n. 1, p. $75-380,2001$

NEGRISOLI, E. et al. Controle de plantas daninhas pelo amicarbazone aplicado na presença de palha de cana de açúcar. Planta Daninha, v. 25, n. 3, p. 603-611, 2007.

NEGRISOLI, E. et al. Eficácia do sulfentrazone em diferentes doses associado à palha de cana-de-açúcar com ou sem chuva após a aplicação no controle de plantas daninhas. In: CONGRESSO BRASILEIRO DA CIÊNCIA DAS PLANTAS DANINHAS, 24., 2004, São Pedro. Anais... São Pedro: SBCPD, 2004. p. 151.

PITELLI, R. A.; DURIGAN, J. C. Ecologia das plantas daninhas no sistema de plantio direto. In: DIAZ ROSSELLO, R. (Coord.). Siembra directa en Cono Sur. Montevideo: PROCISUR, 2001. p. 203-210.

ROCHA, D. C. et al. Efeito de herbicidas sobre quatro espécies de trapoerabas. Planta Daninha, v. 25, n. 2, p. 359-364, 2007.

RODRIGUES, B. N.; ALMEIDA, F. S. Guia de herbicidas. 5.ed. Londrina: 2005. 592 p.

ROSSI, C. V. S.; ALVES, P. L. C. A.; MARQUES JÚNIOR, J. Mobilidade do sulfentrazone em latossolo vermelho e em chernossolo. Planta Daninha, v. 23, n. 4, p. 701-710, 2005.

Planta Daninha, Viçosa-MG, v. 27, n. 4, p. 831-840, 2009 
STREIBIG, J. C. Herbicide bioassay. Weed Res., v. 28, n. 6 , p. 479-484, 1988.

TOLEDO, R. E. B. et al. Eficácia do herbicida amicarbazone aplicado sobre a palha ou no solo no controle de plantas daninhas na cultura de cana-de-açúcar. Planta Daninha, v. 27 , n. 2 , p. $319-326,2009$
VELINI, E. D.; NEGRISOLI, E. Controle de plantas daninhas em cana crua. In: CONGRESSO BRASILEIRO DA CIÊNCIA DAS PLANTAS DANINHAS, 22., 2000, Foz do Iguaçu.

Anais... Foz do Iguaçu: SBCPD, 2000. p. 148-164.

VIVIAN, R. et al. Persistência de sulfentrazone em argissolo vermelho-amarelo cultivado com cana-de-açúcar.

Planta Daninha, v. 24, n. 4, p. 741-750, 2006. 